\title{
PENERAPAN SMS GATEWAY SEBAGAI CUSTOMER TOUCHING APPLICATION UTNUK MELAYANI KEBUTUHAN INFORMASI PELANGGAN PADA PT.SUKSES GEMILANG JAYA ABADI
}

\author{
Andrees Son*1 \\ ${ }^{*}$ Program Studi Sistem Informasi \\ Fakultas Ilmu Komputer \\ Universitas Bandar Lampung \\ Jl. Zainal Abidin Pagar Alam No. 26 \\ Labuhan Ratu Bandar Lampung 35142
}

\begin{abstract}
Pelanggan merupakan aset bagi perusahaan. Oleh karena itu perusahaan berusaha untuk mempertahankan loyalitas pelanggannya, karena efek yang dapat ditimbulkan dari loyalitas pelanggan adalah pembelian yang berulang, kesediaan pelanggan untuk merekomendasikan kepada orang lain. Pelanggan merupakan suatu alat yang dapat membantu menyimpan dan menampilkan data-data pelanggan perusahaan. Data-data yang di perlukan antara lain: data profil pelanggan, data transaksi, dan data produk. Sistem ini kemudian dapat digunakan untuk memberikan informasi mengenai pertambahan jumlah pelanggan perusahaan, pertambahan transaksi dan harapan pelanggan terhadap produk perusahaan. Dari hasil pengolahan data-data tersebut, perusahaan melalui manjemen melalui manajmenen dapat mengambil kebijakan sesuai informasi yang ditampilkan. Perangkat yang diperlukan dalam merancang aplikasiini adalah: PHP sebagai bahasa scripting, Gammu, dan Xampp sebagai pengolah database. Dan untuk menampilkan data dari database digunakan web browser. Aplikasi ini dapat dijadikan alat bantu Monik Clothing dalam memberikan informasi Analitical. CRM ini dapat mengetahui secara lebih mendetail mengenai profile dan segmentasi pelanggan, kebutuhan pelanggan, pola interaksi dan transaksi, serta penjualan dan produk sebagai acuan dalam menentukan strategi CRM pada kegiatan pemasaran, perancangan produk untuk mempertahankan pelnggan.
\end{abstract}

\section{PENDAHULUAN}

\subsection{Latar Belakang}

Ketatnya persaingan dalam dunia bisnis pada saat ini, membuat para pelaku bisnis harus cermat dalam usaha untuk mendapatkan pelnggan baru dan mempertahankan pelnggan yang ada. Banyaknya pilihan terhadap penawaran dan fasilitas yang disediakan, tentu akan memberikan kemudahan bagi pelnggan untuk berpindah dari satu perusahaan keperushaan lain yang memberikan pelayanan yang lebih baik, sehingga kepuasan pelanggan dapat tercipta hubungan yang baik di antara perusahaan dengan pelanggan. Gartner Inc telah mengidentifikasi 10 teknologi yang akan memiliki dampak paling besar - positif dan negatif - pada industri asuransi jiwa. Salah satunya adalah dengan Penjualan dan Layanan Pelanggan Solusi CRM. Penyebaran informasi melalui media surat, dapat digunakan sebagai cara yang baik. Akan tetapi, teknologi SMS yang memiliki nilai lebih dalam usaha untuk memberikan pelayanan dan kepuasan bagi pelanggan. Disamping harga SMS sekarang jauh lebih murah dari pada pengiriman lewat pos, pelayanan lewat SMS juga lebih cepat. Berikut perbandingan harga pengiriman lewat pos dan tarif
SMS beberapa operator seluler: Kebijakan terakhir tahun 2002, Tarif perangko berkisar Rp 1.500 sampai 3000, untuk operator telkomsel (AS) kirim 3 sms berbayar RP. 150/SMS langsung mendapatkan 5000 SMS ke semua Operator. Untuk operator indosat (IM3) gratis 240 SMS perhari dengan persyaratan minimal pulsa Rp 1000 - 2400 untuk 100 sms dan > 2400 untuk 240.

\section{Landasan Teori}

\subsection{Evaluasi Kinerja Dosen}

Berdasarkan uraian latar belakang penelitian diatas, maka masalah yang akan diteliti adalah : Sulitnya pihak perusahaan untuk mengurangi biaya yang dibutuhkan dalam pengaksesan maupun penyampaian informasi, mempertahankan pelnggan dan meningkatkan pelayanan informasi kepada pelanggan.

\subsection{Ruang Lingkup Masalah}

Penelitian ini memilki ruang lingkup yang meliputi sulitnya pihak perusahaan untuk meningkatkan pelayanan informasi yang diberikan kepada pelnggan dan biaya yang relatif mahal dalam pengaksesan maupun penyampaian informasi. 


\subsection{Rumusan Masalah}

Berdasarkan ruang lingkup diatas, maka rumusan masalah pada penelitian ini adalah : "Bagaimana cara mengembangkan aplikasi untuk perusahaan dalam mempermudah pelayanan kebutuhan informasi pelnggan sekaligus meminimalisasi biaya dalam pengaksesan maupun penyampaian informasi "?

\subsection{Tujuan dan Manfaat Penelitian 2.4.1 Tujuan Penelitian}

Tujuan dari penelitian ini adalah :

Untuk mengevaluasi bagaimana aplikasi pelayanan kebutuhan informasi untuk perusahaan dapat mempermudah pelayanan kebutuhan informasi pelnggan dan dapat meminimalisasi biaya.

\subsubsection{Manfaat Penelitian}

Adapun manfaat yang dapat diperoleh dari penulisan ini diantaranya adalah :

1. Manfaat Praktis adalah perusahaan dapat melayani kebutuhan informasi pelnggan melalui media komunikasi SMS, tanpa terbatas tempat dan waktu. Serta mempermudah dan mempercepat usaha dalam penyebaran informasi.

2. Manfaat Teoristis adalah Sebagai bahan informasi tambahan bagi yang ingin meneliti lebih lanjut mengenai hal - hal yang berhubungan dengan penelitian ini.

3. Manfaat Kebijakannya adalah perusahaan dapat meningkatkan kepuasan pelnggan. Dan pemnafaatan teknologi ini dapat meningkatkan image yang baik bagi perusahaan untuk menarik pelnggan baru.

\section{LANDASAN TEORI}

\subsection{Tinjauan Pustaka}

Menurut Kalakota dan Robinson (2001), CRM didefinisikan sebagai interigasi dari penjualan, pemasaran dan strategi pelayanan yang membantu perusahaan agar lebih baik dalam menangani hubungan dengan pelnggan dengan melakukan interaksi dengan berbagai cara. Menurut Kalkota dan Robinson (2001) memiliki tujuan - tujuan sebagai berikut:

1. Menggunakan hubungan yang sudah ada utuk meningkatkan pendapatan.

2. Menggunakan informasi yang terintegrasi untuk meningkatkan pelayanan yang memuaskan

3. Menciptakan saluran proses dan prosedur komunikasi dengan pelanggan.

\subsection{SMS Gateway}

Istilah gateway dapat diartikan sebagai pintu gerbang namun pada dunia komputer ,gateway dapat diartikan sebagai jembatan penghubung antara satu sistem dengan sistem yang lain, sehingga dapat terjadi pertukaran data antara sistem tersebut .

\subsection{Perangkat komuikasi}

Perangkat komunikasi sistem gateway merupakan perangkat yang dapat digunakan untuk mengirim atau menerima SMS.perangkat tersebut dapat berupa :

a. Telepon seluler ponsel

Agar dapat terhubung ke komputer,ponsel harus memiliki dukungan konektivitas ke perangkat lain seperti kabel data ,bluetooth,atau infra merah.

b. GSM modem

GSM modem merupakan sebuah modem wareles yang bekerja dengan GSM.bila modem biasa menggunakan kabel telepon untuk transfer data,maka GSM modem menggunakan gelombang radio sebagai medianya.

c. GPRS modem

Perbedaan mendasar antara GMS modem.GPRS modem adalah tambahan dukungan tekolongi GPRS pada transmisi datanya.

GAMMU (All Mobile Management Utiliti). Gammu adalah sebuah perangkat lunak yang di kembangkan oleh Marcin wiacek pada bulan april tahun 2005 kemudian dilanjutkan oleh Michal cihar pada bulan januari 2007 yang fungsinya adalah memindahkan texs SMS dari perangkat handphone dari media lainnya seperti komputerdan sebaliknya. Kelebihan Gammu dari tool SMS gateway lainnya adalah :

1. Gammu dapat dijalankan di sistem operasi Linux maupun Windows.

2. Banyak device yang kompatibel di Gammu.

3. Gammu menggunakan database MY SQL untuk menyimpan SMS yang ada yang ada pada kotak masuk (inbox) maupun untuk mengirim pesan ,sehingga dapat dibuat interface yang berbasis wab maupun dekstop.

4. Baik kabel data USBmaupun serial ,semuanya kompatibel di Gammu.

UML merupakan suatu bahasa yang digunakan untuk menentukan,memvisualisasikan ,membangun,dan mendokumentasikan suatu sistem 
informasi.terdapat 10 macam model UML untunk memodelkan aplikasi berorientasi objek,tetapi hanya 4 macam diangram yag paling sering digunakan dalam perancangan pembangunan program berorientasi objek, yaitu:

1. Use Case Diagram

Use case diagram menggambarkan fungsionalitas yang diharapkan dari sebuah sistem .Yang ditekankan adalah "apa" yang diperbuat sistem , dan bukan "bagaimana".



2. Class Diagram

Class adalah sebuah spesifikasi yang jika diinstansikan akan menghasilkan sebuah objek dan merupakan inti dari pengembangan dan desain berorientasi objek.

3. Sequence Diagram

Sequence Diagram adalah suatu diagram yang memperlihatkan/menampilkan interaksi interaksi antar objek di dalam sistem yang di susun pada sebuah urutan atau rangkaian waktu.

4. Activity Diagram

Activity diagrammenggambarkan berbagai alir aktitivitas dalam sistem yang sedang dirancang, bagaimana masing masing alir berawal, decision yang mungki terjadi, dan bagaimana mereka berakhir.

Metodologi

Penelitian

Analisa kebutuhan diperlukan dalam rangka analisa kebutuhan dalam perancangan sebuah sistem maupun program aplikasi.Setelah proses analisa kebutuhan dilakukan dengan benar maka kebutuhan sistem dapat diketahui dengan tepat.

\subsection{Perancangan Penelitian}

Use Case Diagram disini di jelaskan secara grafisdengan menggambarkan iteraksi antara sistem dan pengguna.

\section{Pembahasan}

\subsection{Sejarah Perkembangan CRM}

CRM merupakan topik yang mengalami perkembangan signifikan khususnya di kiasaran 10 tahun terakhir.Namun amat penting juga mengetahui awal perkembangan CRM untuk memahami gambaran besar pertumbuhan CRM di dunia bisnis dan riset.

\subsection{Sasaran dan tujuan CRM}

Manajemen hubungan pelanggan (bahasa Inggris: Customer Relationship Management disingkat CRM) adalah suatu jenis managemen yang secara khusus membahas teori mengenai penanganan hubungan antara perusahaan dengan pelanggan nya dengan tujuan meningkatkan nilai perusahaan di mata para pelanggan nya.

\subsection{Konsep dan Aktifitas CRM}

CRM adalah strategi tingkat korporasi, yang berfokus pada pembangunan dan pemeliharaan hubungan dengan pelanggan.Beberapa paket perangkat lunak telah tersedia dengan pendekatan yang berbeda -beda terhadap CRM.

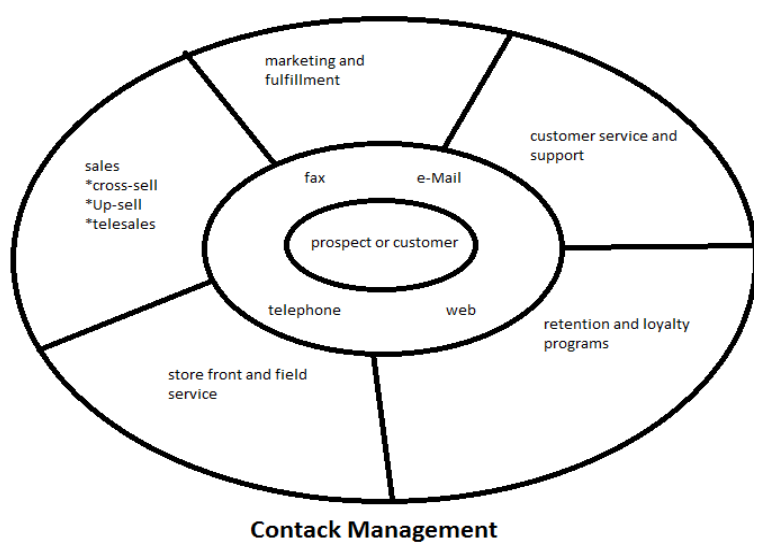

1. Membangun database pelanggan yang kuat Database pelanggan yang kuat merupakan kunci utama pelaksanaan CRM. 
2. Membuat profil dari setiap pelanggan Langkah selanjutnya adalah membuat profil dari masing-masing pelanggan.

3. Analisis Profitabilitas dari tiap-tiap pelanggan Ada 2 hal yang di nilai dari masing-masing pelanggan.

4. Interaksi dengan pelanggan yang lebih targeted dan customized

Dengan profil yang lebih jelas, perusahaan akan lebih mudah utnuk melihat kebutuhan yang berbeda-beda dari setiap pelanggan.

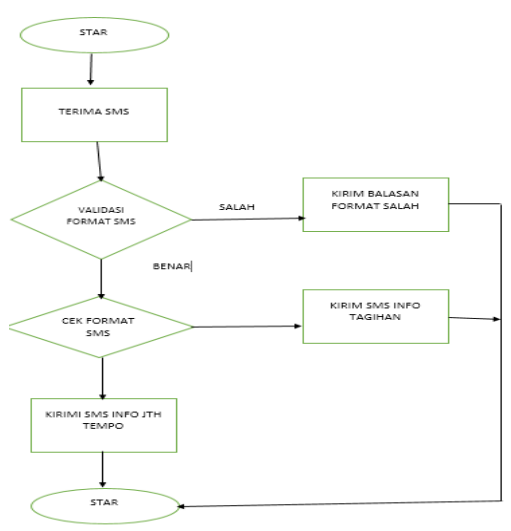

Flowchart SMS minta info

\subsection{Simpulan dan Saran}

\subsubsection{Simpulan}

1. Teknologi SMS dapat membantu mengatasi kesulitan perusahaan dalam penyebaran informasi kepada pelanggan yang tersebar di berbagai daerah.Karena SMS memberikan kemudahan dalam mengakses informasi.

2. Biaya Penyampaian informasi dapat diminimalisasikan dengan pengguna SMS, karena SMS memiliki biaya yang jauh lebih murah untuk setiap kali pengaksesan informasi dan dapat dilakukan dengan cepat.

\subsubsection{Saran}

1. Aplikasi ini sebaiknya dikembangkan lagi agar sistem dapat memonitoring terhadap pesan yang telah dikirmkan apakah SMS telah sampai ditujuan atau belum.
2. Perusahaan dapat mempertimbangkan untuk bekerja sama dengan operator seluler.

3. Juka ditinjau dari segi pengukuran data maka penulis merekomendasikan operator seluler yang dipakai adlah Telkomsel (AS), karena dengan selisih biaya Rp.43.200 utnuk pengiriman seluruh indonesia (nasional).

\section{Daftar Pustaka}

1. Wahidin.2010.Aplikasi SMS dengan Php untuk orang awam.Palembang:Maxikom

2. Gunawan,Wahyu.2010.Kebut sehari jadi master PHP.Yogyakarta:Genius Publisher.

3. CRM with Marketing Comunication. http://www.ciptamaya.com/news_seminar1602. .html.

4. Danardatu,aloysius Heru.2003.Pengendalian Customer Relationship Management (CRM).http:ikc.dephan.go.id/umum/herucrm.php.pp2-3.

5. Satriyono,toni.2001.Tantangan Aplikasi wirelles

3G.http://satriyono.net/works/paper1.html.

6. andrew.cmu.edu/course/90-754/umlucdfaq.html Dreamfabric.com/sms/ 